\title{
Promoting Discovery: Creating an In-depth Library Marketing Campaign
}

\begin{abstract}
This case study aims to describe how librarians at Indiana University Kokomo designed a marketing campaign to promote its discovery tool to undergraduate students during the Fall 2012 semester. The authors illustrate how, through the use of a coordinated marketing plan, librarians applied marketing principles to select a target audience, create promotional designs, organize events, and assess campaign effectiveness. The authors express how libraries can construct cost-effective yet comprehensive marketing campaigns, as well as learn from both unexpected successes and shortcomings of such projects. Ultimately, these takeaways can inform a library’s future marketing endeavors.
\end{abstract}

Keywords: marketing, promotion, discovery, discovery service, library services

"About the Authors"

Angie Thorpe received her MLS from Indiana University and her BA in English from the University of Wisconsin-Madison. Her research interests include discovery services, the marketing of e-resources, and using data to make collection and content decisions. She currently serves as the Digital User Experience Librarian at Indiana University Kokomo. She can be contacted at atthorpe@iuk.edu.

Heather Bowman received her MLIS from Indiana University-Purdue University at Indianapolis and her BA in History-Political Science from Indiana University Kokomo. She served as the Electronic Resources Assistant/Department Secretary at Indiana University Kokomo until August 2012. She currently serves as the Electronic Resources/Serials Librarian at Wilkes University in Wilkes-Barre, Pennsylvania. She can be contacted at heather.bowman@wilkes.edu.

Received: August 14, 2013

Accepted: September 10, 2013 
Promoting Discovery: Creating an In-depth Library Marketing Campaign

Many libraries are investing significant sums in discovery service products, tools that unite remotely-licensed and locally-held resources within a single index that offers a single search box and navigable results (Vaughan, 2012). As a result, library users can use discovery services to simultaneously search full-text articles and multimedia databases, library catalogs, government document collections, and more with single search queries. Henrietta Thornton-Verma wrote in late 2011 that "Discovery services promise to enable all of a library’s material - print and e-books, journal articles, streaming video, everything - to be uncovered through one search box” (p. 14). If the promise of discovery services is to be met, though, before libraries assess the effectiveness of these tools, they must first get the word out that they have these products.

This article reports on a marketing campaign undertaken by the library faculty and staff at Indiana University (IU) Kokomo during the Fall 2012 semester. The intent of the marketing campaign was to increase awareness of the library's discovery service and officially brand the discovery service as EDS for the university community. Since IU Kokomo had not recently organized a marketing campaign to promote a specific electronic resource, the authors were also curious to observe the effects a targeted campaign might have on usage statistics for a chosen e-resource. The results of this promotional campaign would then be used to inform the planning and execution of future marketing efforts at the library. In broader strokes, the value of this article is to share how libraries - including small ones with limited resources both in terms of people, time, and funding - can design cost-effective yet still comprehensive marketing campaigns and then learn from both the successes and shortcomings of their projects. The authors' intent is to inspire other libraries to develop promotional campaigns and be unafraid to acknowledge the times when results fall short of expectations. Ultimately, there are positive takeaways from any project, which can and should be used to shape processes the next time around.

\section{The Situation}

IU Kokomo, located in north central Indiana, is a regional campus of Indiana University. The student population at IU Kokomo is approximately 3,700, of which about $96 \%$ are undergraduates (Indiana 
University Kokomo Campus 2012-13 Fact Book). The campus offers associates, bachelors, and masters degrees in eight academic schools, colleges, or divisions, including the Division of Allied Health, the School of Humanities and Social Sciences, and the School of Nursing. The IU Kokomo Library, as of 2011-2012, houses a collection of 138,653 print volumes and dozens of electronic databases, including electronic serial packages (Indiana University 2012-13 Fact Book). The library’s four librarians and dean do not have formal liaison responsibilities to specific departments, but they communicate product news to faculty, as well as encourage material recommendations from all patrons. Orders for print and electronic resources are primarily completed by the Digital User Experience Librarian and the Technical Services Librarian. Usage statistics are compiled by the Digital User Experience Librarian and Electronic Resources Assistant/Departmental Secretary every fiscal year. The librarians refer to usage statistics when discussing renewals within the department and with other faculty members. Usage statistics are not the sole deciding factor for renewals, but they do carry weight. The librarians have discussed whether usage data is a fair metric, since some resources receive more "air time” because they are general and/or more familiar to the librarians. This prompted the librarians to wonder whether direct marketing campaigns for resources would have an effect on usage statistics. Since the library had not carried out a coordinated marketing plan in at least a few years, the library employees decided that a promotional campaign might be a strategic way to increase awareness of library resources and/or services while simultaneously increasing usage of any promoted resources and/or services.

\section{Literature Review}

Marketing is not a new concept for libraries, and much has been written about this topic. Library marketing literature shows an evolution of the meaning, and librarian perceptions of the necessity, of marketing in libraries. The earliest association between "libraries” and "marketing” found by the authors when searching the Library, Information Science \& Technology Abstracts database was a piece written by John Berry in Library Journal (1979). Berry cautioned the tagging of library public relations efforts as "marketing," acknowledging an ability to gain public support by marketing goods and services while also 
recognizing the potential turnover of any marketable goods to expert marketers in the private sector (p. 1605).

By the 1980s, librarians were beginning to recognize the need to adopt the business concepts, including marketing, within libraries. Wood (1983) and Conroy (1984) advocated for the adoption of strategic planning and marketing initiatives within libraries, with Wood warning that "any of us [those in the library profession] who remain suspicious of or hostile to the idea of marketing libraries may not survive the mounting problems and pressures in our field of endeavor” (p. 15). Dragon and Leisner (1984) also encouraged the development of library marketing programs in order to position the library in the minds of the public and gain recognition from the library’s community. This literature likely encouraged many libraries to implement marketing initiatives, leading to reviews of what worked for specific libraries in the 1990s. Fleming (1993), for example, described how the Charlotte \& Mecklenburg County Public Library in North Carolina was transformed from a languishing institution into a thriving one via a visionary marketing plan that emphasized building relationships and services with community members and organizations. In 1993, American Libraries reported a more tangible effort by the Salt Lake City Public Library to raise awareness of library services: the library distributed its annual report in clear plastic shopping bags that also contained details on services provided by the library, such as items checked out, in-use library use of materials, and total attendance at library programs.

This literature has progressed into a voluminous field since 2000, with three primary categories emerging: explanations of the role marketing can play in libraries, general tips for implementing marketing plans, and case studies of libraries who have implemented campaigns. The first category focuses upon describing how marketing can help libraries. Mathews (2009), Singh (2004), and MetzWiseman and Rodgers (2007) fall into this category by setting the stage and explaining the role marketing can and should play in libraries. Metz-Wiseman and Rodgers (2007), for instance, chronicle their library’s transition from a marketing team of volunteers to its creation of a dedicated Communication Manager position that reports to the dean of the library system. Their experience highlights the growing importance of, and distinction between, public relations and marketing for libraries. The authors effectively argue 
that, with increasing competition from non-academic sources, libraries need to continue promoting awareness of resources and communicate their relevancy in order to keep the library at the center of university life (Metz-Wiseman \& Rodgers, 2007). Mathews (2009) explains that marketing methods in libraries can create richer library experiences for and achieve more meaningful connections with their users. By engaging with our users through marketing initiatives, we can develop relationships that allow us to better communicate our value to our user communities.

A second category of marketing literature moves from the theoretical question of the role marketing can play in libraries to general marketing tips and suggestions for libraries. Dillon (2003) explains different types of marketing strategies libraries can adopt: relationship marketing, which focuses on close and frequent contact in order to convey an ongoing value to customers; positioning of products in terms of value for the customer; and incorporating marketing into library leadership activities, such as featuring a newly purchased database on the library's homepage in order to inform users of the new resource. Fagan (2009) offers specific suggestions for marketing online resources, including creating “canned searches” for resources within the library’s online catalog, optimizing the library’s web site for search-engine indexing, creating landing pages on the library web site for promotional materials, and placing online ads - either on the library web site or other sites - for resources. Both Wisniewski and Fichter (2007) and Woods (2007) offered step-by-step instructions for marketing electronic resources. Wisniewski and Fichter provided six steps for guiding a marketing campaign, from defining a market to evaluating efforts. Woods, on the other hand, offered a three-step approach - instruction integration during orientation sessions, placing ads for resources on the library Website, and targeted e-mails to faculty and staff - for marketing electronic resources.

The third literature category - case studies - explores how libraries have applied marketing theories and recommendations into their organizations. The variety of library types and sizes translates into a multitude of approaches libraries have taken in terms of actual marketing campaigns. A select few examples highlight this assortment: Brannon (2007), Empey and Black (2005), and Dugan (2011) each described case studies of electronic resource marketing initiatives at their respective institutions. 
Collectively, the authors described several paths libraries might take with their marketing efforts, including handing out promotional materials, such as pens, pencils, and magnets (Brannon, 2007); displaying themed posters and panels for library resources, services, and collections (Empey \& Black, 2005); and sending promotional e-mails to faculty (Dugan, 2011). The varied marketing paths reflect the different objectives libraries may have in undertaking marketing campaigns. Objectives described by the aforementioned authors included trying to increase appreciation and awareness of library resources and services, increase electronic database usage statistics, and increase faculty familiarity with the tools and benefits of discipline-specific resources.

Our article falls into this third category, as we describe how our library implemented a marketing campaign to promote our discovery service in Fall 2012. To plan our campaign, however, we drew heavily on the guidelines provided by Wisniewski and Fichter (2007). Our study documents how guidelines can translate into an organized marketing plan that involves coordination across multiple university departments beyond the library. Our study is unique in that we describe how a discovery service might be marketed to a targeted population of university users and how the marketing campaign can effectively brand the discovery service for the library and university community.

\section{Setting}

The IU Kokomo Library licensed the EBSCO Discovery Service (EDS) in May 2011 after trialing a beta of the product from 2009-Spring 2011. Usability testing with IU Kokomo students was conducted during the beta period, with the key takeaways being that users appreciated the familiar interface but did not necessarily see full-text article links or sidebar navigation options upon first look. The library unveiled EDS to its user population via a library homepage redesign in September 2011, in which the new, as-yet unbranded single search box was centrally placed. The library's interactive webbased tutorials and graphics were updated with screenshots of the redesigned homepage. A new web page entitled, “EDS: What am I searching?” was created in an FAQ format and featured answers to questions such as, "What is EDS?”, “What does it do?”, and “How is it different from other databases I've used?” Blurbs about EDS were added to several web pages, including the library’s "Finding Information” guide, 
a digital library resources page for faculty, and a library resource overview page for campus visitors. The only publicity efforts undertaken to announce the launch of EDS were an e-mail message sent to all campus faculty and staff in October 2011 and a press release issued by the campus' media and marketing office in February 2012.

Prior to the discovery service launch in September 2011, the library staff discussed branding approaches for the product. We compiled a list of potential discovery service names, based upon those already in use by other subscribing libraries. Such names included Quick Search, Discover(y), MultiSearch, OneSearch, and SuperSearch, to name a few. After discussion, though, we felt that branding was not an immediate priority. Rather, we were interested in observing whether students gravitated toward and used the simple, single search box on the library's homepage. Before branding, we wanted to observe whether the search box spoke for itself.

In the spring of 2012, however, the branding conversation resurfaced when the library staff began to consider launching a marketing campaign for EDS. During the intervening 7 months since its launch, we had realized that, intentionally or not, we had come to refer to the discovery service as EDS. EDS had been an internal term used in conversations among staff members during the product's beta period. Since the launch of EDS, however, we had also come to use this term when interacting with students and faculty at the library's Ask a Librarian service desk and while teaching information literacy sessions. It was not uncommon to hear a librarian tell a student, “This search box on our homepage searches pretty much everything we have. It's called EBSCO Discovery Service, or EDS for short.”

At the same time, in initially unrelated conversations, the library faculty and staff began discussing the library's strategic planning objectives for the upcoming 3 years. Several of the library’s goals centered upon increasing use of the library, whether through circulation counts, information literacy sessions, full-text article downloads, or other methods. During these conversations, the authors suggested launching a marketing campaign in order to demonstrate how the library's resources add value to the campus community. The rationale behind this suggestion was that, in order to increase use of the library, the university community first needed to be aware of what the library had to offer. The library dean 
approved the formation of a task force to investigate a concerted marketing effort and appointed the Digital User Experience Librarian as task-force chair. The marketing task force consisted of the library’s faculty librarians and one staff member, with the dean being brought in as necessary to contribute ideas and issue project approvals.

\section{Process}

In preparation for the first meeting, the authors asked the task force to read a short article that explained marketing steps for libraries, including defining a market, deciding what to promote, creating a marketing plan, conveying a message, selecting a location and medium, finding a production team, and establishing evaluation criteria (Wisniewski \& Fichter, 2007). The task force met throughout Spring and Summer 2012 to discuss these marketing steps.

\section{Deciding What to Promote}

Although the Digital User Experience Librarian chaired the task force, marketing an electronic resource was not a foregone conclusion. The products/services considered for promotion also included one or all six of the library's streaming video collections, as well as the library's information literacy instruction service. The task force ultimately decided to market the EBSCO Discovery Service because of the practicality of discovery services to student research and assignments.

\section{Defining a Target Audience}

After deciding what to market, our next step was to determine the audience we wanted to reach. According to Wisniewski and Fichter (2007), a focused marketing campaign should target a specific audience with a core idea rather than selling a broad concept to the entire community. The task force discussed the merits of promoting EDS to faculty, to students, or to faculty and students. Experience shows that students tend to use resources recommended by their professors, so outreach to faculty had the potential to make EDS visible in classrooms. That plan, however, required faculty to buy into the value of EDS, and with a technology tool as new as a discovery service, that outcome was not guaranteed. Individual faculty members may dislike EDS or like it but still decide against mentioning or demonstrating it to their classes. Therefore, the task force decided to market EDS directly to students. In 
doing so, the library retained control over the message students received about EDS and the manner and timing in which that message would be conveyed. We kept faculty informed of our interactions with students regarding EDS via campus-wide announcements and events hosted by the Center for Teaching, Learning, and Assessment (CTLA), such as new-faculty orientation and the annual adjunct-faculty dinner, but we did not gear the campaign specifically to faculty.

The task force also discussed whether to target a specific school or department. Given the nature of a discovery service as a tool for multidisciplinary research and the presentation of it as a single search box, we decided against limiting our target audience to certain schools, as that would undermine the underlying message of the marketing campaign.

The task force, however, did decide to market EDS to only undergraduate students. The unique research needs of graduate students require a separate, targeted message that is different from the one promoted to undergraduate students. The task force felt that we could better address graduate student research needs with another marketing campaign in the future.

\section{Venue and Media}

IU Kokomo is a commuter campus with a growing emphasis placed on online classes and resources. The library also sees heavy foot traffic in the building when classes are in session because most of the campus computers and two computer labs are located inside the library. The combination of virtual and physical library usage suggested that, to create an effective campaign, we would need to reach students both online and in person.

To achieve an online presence, we could use the library’s web site and campus social media sites to promote EDS and campaign events. In person, we could include promotional materials in student orientation packets, request an article in the student newspaper and a segment on the campus TV and radio stations, send a mass e-mail announcement, post an announcement on the campus-wide digital signs, and/or write an article for the library's newsletter. In discussing these options, we realized that pursuing every communication option would be impractical for a small task force and could potentially oversaturate our audience. We decided to focus our efforts on library web site and e-mail announcements, 
campus digital signs, and promotional material giveaways. We chose bookmarks and post-it notepads that featured our EDS design as promotional materials, which cost approximately $\$ 500$ total.

\section{Honing the Message}

According to Wisniewski and Fichter (2007), a successful marketing campaign conveys a benefit, not a thing. The task force unanimously agreed that the benefit of EDS to students is its "oneness"; that is, its ability to search most of the library's resources from a single search box. We decided that this was the idea that would best capture students' interest. In coming up with a slogan, we tried to be brief and speak to the rule, not the exception. Librarians tend to qualify and provide instructions for every eventuality. While it's fine, perhaps preferable, to say to a user at the reference desk, “This should be the only place you need to search,” that is a weak slogan for a marketing campaign to adopt. In brainstorming slogans, we avoided words that in any way limited the oneness benefit of EDS. Some potential slogans included “gateway to library resources”, “one box searches everything”, “find it fast; get it now”, “search one and done”, and a number of alternative phrases using the EDS acronym, such as "Enjoy. Discover. Succeed.”, "Expect to Discover Something”, and "End Desperate Searching," all of which related to the oneness of EDS. We ultimately decided on the slogan " 1 and done. End Desperate Searching”, with the first letters in “End Desperate Searching” boldfaced to correlate with the EDS brand name.

\section{Design}

Amid the discussion of which slogan to use, we sketched out a rough design of a promotional poster. Using the design idea of a Wordle, which is “a piece of text which has been rearranged into a visual pattern of words" (Maxwell, 2009), we shaped the Wordle in the form of a number 1 with the words "and done” underneath to create the phrase " 1 and done.” At the top of the page, we wrote "End Desperate Searching” with the capital E, D, and S letters boldfaced in order to tie the slogan to the name of the promoted product. Although this was just a preliminary mock-up, the task force liked the concept and decided to use this image idea for the campaign. Via e-mail, the authors asked all library faculty and staff for a list of 20 words that they thought of when they heard the word "library.” We used the compiled list to create a Wordle using the online tool Tagxedo.com (http://www.tagxedo.com/), which easily allows 
users to create Wordles in any shape by uploading vector images. The collection of words in our Wordle included some expected items, such as "librarians" and "books", but also some unique and interesting connotations such as “communication”, “enrichment”, and "peaceful.” The authors then created a poster in Adobe Photoshop CS4, which the task force approved.

IU Kokomo policy requires any promotional materials be submitted to the campus media and marketing department for approval prior to use. The authors met with the Director of Media and Marketing to review the poster, explain how and where we intended to use the design, and discuss any other issues that might arise. The director supported our ideas and design but wanted to slightly redesign the image so that it more closely matched other promotional images in use by campus departments. The authors worked closely with media and marketing's Graphic Design Specialist to discuss the purpose and message of the poster, to review revisions, and to seek approval from the task force on subsequent drafts of the image. The changes made by the media and marketing department included altering the color scheme to match university colors, enlarging the library's logo, and removing the EBSCO and Tagxedo icons at the bottom of the image. The task force was primarily pleased with the new design, with the only change request being to restore the library's web site to the design, as it had been removed in one design iteration. Because the promoted resource was both web-based and prominently featured on the library's homepage, the task force felt this was an essential component for the promotional design. We requested this addition, along with an invitation to "Try EDS," and, when these changes were incorporated, the task force approved the design. Figure 1 presents our final promotional design with our Wordle and slogan. This design was used in both our promotional materials and our publicity messages to announce campaign events.

\section{[PLACE FIGURE 1 HERE]}

\section{Events}

In addition to creating neat promotional designs to market our discovery service, we also decided to host promotional events for our end users. We coordinated two primary events for this campaign: an open house for students and a "brown bag” lunch info-session for faculty. Prior to scheduling the open 
house, the Dean of Students and campus calendar were consulted in order to identify a few lightlyscheduled dates in early Fall 2012. The date of September 12, 2012 was targeted as a preferred date. With the date in mind, the authors worked with the campus events planning team to reserve a location for the open house. The space that was selected was Alumni Hall, a large indoor corridor that connects the library building with the student center and was popular as a between-classes thoroughfare and break spot for students. (The hallway is physically located outside the library proper; the IU Kokomo library building space includes the library as well as a small auditorium, the campus art gallery, a conference room, restrooms, and storage closets.) Requests were also made to the events-planning team for table setup and refreshments delivery on the day of the open house. Within the library, plans were made to use the library's two tablets and a laptop during the open house so that students could "test drive” EDS. The Digital User Experience Librarian also created note cards with 20 or so sample search queries for students to use, in case they were unable to think of a search query on the spot.

Although the marketing task force’s primary target audience was the campus’ population of undergraduate students, and that was indeed the target audience for the open house, we also wanted to hold an event for faculty so they would know what the library was promoting in our flyers, giveaways, and web site should any of their students ask them about EDS. Furthermore, it was also hoped that faculty would be inspired to take advantage of EDS's broad and deep-searching capabilities for their own research. To that end, the authors coordinated with the IU Kokomo CTLA to deliver a brown-bag lunch session entitled, “Reinvigorating Research Strategies with the Library’s Discovery Service,” led by the Digital User Experience Librarian.

\section{Evaluation plan}

With many of the details decided, the final component of our promotional strategy was to determine an evaluation plan for our campaign. The task force considered numerous evaluation options, including a web-based and/or paper survey, before and after database usage statistics, event attendance counts, material distribution counts, service-desk statistics, one-minute responses in instruction sessions, and asking students to provide feedback on whiteboards around the library. Based on time and other 
constraints, we eventually decided to add a question about EDS to the standard instruction-session evaluation form, count event attendance, and compare before and after usage statistics to assess the success of our campaign.

\section{Results}

The EDS open house was advertised via digital signs on TV monitors located around campus, as well as an announcement on the library’s homepage. Figure 2 shows the promotional design - a modification of the design used for promotional materials - that we used for open-house announcements.

\section{[PLACE FIGURE 2 HERE]}

The open house was held over the lunch period of 11:00-12:30pm on September 12, 2012. The authors worked with the campus events-planning team and the Reference and Information Services Librarian to set up two tables in Alumni Hall, upon which we also set up two iPads and a laptop for students to use in order to test EDS. Two lemonade dispensers, costing approximately $\$ 50$ total, were arranged to provide refreshments for attendees.

During the event, we recruited visitors by asking passersby whether they were interested in trying the library's discovery product and, occasionally, whether they would simply like a cup of lemonade. Both strategies worked, and we spoke with a steady stream of attendees. In total, 42 students and faculty visited the open house. Several students commented that they had already used EDS and had found it to be useful. In such situations, we took the opportunity to teach users about the advanced features in EDS, such as source type and content-provider limiters, as well as how to use EDS to search within specific publication titles.

We experienced a few hiccups with the technologies we selected for testing EDS, such as a laptop not retaining a battery charge, but these issues ultimately did not detract from the success of the event. In fact, an indirect benefit of the open house was that, since we provided tablets for testing purposes and some students self-commented they had never used a tablet before, students were able to observe how 
library resources could display on new technology devices. We deemed this a value-add for the open house, as it helped demonstrate how the library is keeping pace with modern technological developments.

One week after the open house, the Digital User Experience Librarian led a brown-bag session on EDS for faculty. This event was publicized via e-mail by the CTLA. The informal session was held from 11:45am-12:45pm on September 20, 2012. Only three faculty attended the session, but this allowed time for both general and on-the-spot custom demonstrations, based on the faculty members’ needs and product knowledge. As with the open house, the success of the event was determined not by the quantity of attendees, as scheduling during a lunch hour may be inopportune for both busy students and faculty, but rather by the quality of the interactions held with attendees. Students and faculty alike commented that the tips they learned were useful and would come in handy for assignments.

In addition to the visitor counts recorded at the two promotional events, the authors also reviewed EDS usage statistics from EBSCOhost in order to gauge the effectiveness of the marketing campaign. Using the EBSCOhost administrative interface, we pulled a variety of statistics for both the Fall 2011 and Fall 2012 semesters, using data from the months of September-December for both datasets. The statistics revealed a somewhat confusing picture: While EDS sessions remained nearly flat year over year (6,860 in 2012; 6,910 in 2011), searches increased by more than 560,000 from 2011 to 2012 (2,623,481 in 2012; 2,057,418 in 2011; see Figure 3). These results suggest that, while users did not access EDS more often during the Fall 2012 semester, they likely refined or revised their search queries more often during this time period.

\section{[PLACE FIGURE 3 HERE]}

The mixed results continued as we next examined our semester/semester user engagement metrics, that is, use of abstracts and retrievals of full texts. The use of abstracts increased $7.3 \%$ year over year (15,039 uses in 2012 vs. 14,011 in 2011), with a curious uptick in usage occurring in December, very 
late in the fall semester. Full-text retrievals did not fare as well, however; usage decreased 7.8\% from 9,103 retrievals in 2011 to 8,397 in 2012 (see Figure 4).

\section{[PLACE FIGURE 4 HERE]}

Finally, we reviewed usage figures for two EDS linking features: "Smart Links To” and “Custom Links Out.” Smart Links connect citations from one EBSCOhost database to full-text articles in a different EBSCOhost database, thereby surfacing full-text articles alongside higher ranking search results (EBSCO Support, 2012). Custom Links, on the other hand, are configured using a customer-controlled URL template; EDS customers use these templates to create links to non-EBSCO full text and other services, such as JSTOR. Our smart link usage decreased 30\% (from 619 uses in 2011 to 433 in 2012) year over year, but our custom link usage increased 55.5\% (from 2,257 uses in 2011 to 3,510 in 2012) (see Figure 5).

[PLACE FIGURE 5 HERE]

\section{Discussion}

The purpose of our marketing campaign was to increase awareness and usage of IU Kokomo’s discovery service. By this measure, we experienced both wins and losses. On the positive side of the spectrum, the turnout at our open house was higher than expected, and the open house attendees were engaged in the test-drive experience. They seemed excited to see how EDS worked on a tablet, as well as learn how to maximize their search processes. On the negative side, however, the turnout at the faculty brown-bag session was low, and several usage data points were disappointing. Since the marketing campaign concluded, we have taken time to reflect on our experiences and identify what worked and what didn't work in the hopes of better informing our future promotional endeavors. 
In terms of what worked, we started off on a strong note: We began our planning several months in advance of our scheduled launch date, allowing ourselves plenty of (or at least adequate) time to determine our marketing message, design, and methods. Although all library employees were invited to attend the first planning meeting, only those who were interested in helping actually attended. This was important because our marketing team was self-selected; team members were predisposed toward being engaged in the library's promotional initiatives, evidenced by the fact that several attendees brought ideas with them to the first meeting. In the first meeting, we transformed a strategy from industry literature (Wisniewski \& Fichter, 2007) into our agenda, as the strategy provided a logical structure for our planning processes. Rather than brainstorming all of our tasks from scratch, we used Wisniewski and Fichter's tips as a guide from which we could jump-start our discussions.

Through the combined marketing materials of digital signs, posters, announcements, and promotional giveaways, the library was also able to successfully and cost-efficiently brand its discovery service with a recognizable and appealing logo and a single name. We collaborated with our campus Media and Marketing team to craft a logo for EDS that is not only eye-catching but also represents the character of our particular library, since the words that comprise the "1" are words that our library employees think of in order to describe our library. The library faculty as a team finally solidified the name of our discovery service. This simplified instruction and reference activities, as we now collectively refer to EBSCO Discovery Service as EDS, rather than “our research tool,” “our discovery service,” “EBSCO Discovery Service,” or any other names. Finally, our entire promotional campaign, including giveaways and refreshments, cost only about $\$ 550$, an economical total for our small library. Having inhouse talent to assist with the creation of our promotional design certainly helped mitigate our expenses. As might be expected with any new undertaking, some aspects of our marketing campaign did not work as we had anticipated. Despite beginning our planning processes several months in advance, we still experienced delays in some steps of our campaign: It took longer than expected to finalize the promotional design with Media and Marketing, so we had to wait longer than expected to order our promotional materials. The frenzy of activity at the beginning of the semester also meant that Media and 
Marketing was swamped at this time, which delayed the push of our open-house announcement to the digital signs around campus. Rather than running for a full 2 weeks prior to our event, as we had initially planned, the announcement appeared on the campus-wide TV signs for only approximately 4 days prior to the event. Additional exposure may have helped increase attendance at the open house, although we did promote the event on the library's web site as well.

Turning to our usage statistics, we did not observe an overwhelming increase in usage from the Fall 2011 to the Fall 2012 semester. We expected to observe an increase in EDS sessions year over year; instead we saw an increase in searches. We expected to see an increase in full-text downloads year over year; instead we saw an increase in abstract usage. Our expectations were based upon the (perhaps faulty) notion that more attention on the discovery service would lead to more usage. In conjunction with more full-text sources available to users in 2012 than in 2011, more usage would then lead to more full-text retrievals. That being said, we did not have a statistical benchmark for EDS usage in place. With barely a full year's worth of recorded data since we officially launched EDS, we felt it unwise to set hard usage targets for our campaign. What if, for instance, our September-December usage statistics for 2011 were an anomaly, and our true usage patterns would emerge in 2012? Even now, when we are approaching 2 years' worth of data, we still cannot be completely confident in our usage patterns. However, we can draw inferences from the data we do have, and, while these inferences may not be what we expected to glean, they will undoubtedly prove valuable nonetheless.

While the number of EDS sessions stayed roughly the same (decrease of 0.7\%) from Fall 2011 to Fall 2012, searches increased by $27.5 \%$ year over year. The nearly flat session statistics may indicate this is our maximum usage level; it is a statistic we will be closely watching for any variations during the Fall 2013 semester. If our Fall 2013 session total closely resembles our previous two sums, we may be able to use the highest of these three figures as our baseline for future fall-semester usage. This would be notable for the library, as we previously have not set usage benchmarks or targets, and having such a figure would allow us to set data-driven departmental goals. The surge in searches is also intriguing and may be explained by a couple of reasons. One reason may be that users do not find the results they want or expect 
with their first search query, so they try a different search query. Singer, Norbisrath, and Lewandowski (2013) found that user behavior on search engines is significantly different depending on whether the user's task is deemed to be simple or complex. A simple task, derived by the researchers, would be to determine the average temperature for a city in July; a complex task would be to determine what differences, if any, exist in religious affiliation distributions among a few European countries. In analyzing the search behavior of 52 participants, Singer et al. found that the number of queries users issued during a task was three times as high for complex search tasks as for simple ones. Since it seems more likely library users would use a discovery service to complete complex tasks than simple, in accordance with their class assignments or research projects, it follows that the behavioral difference from general web search engines would also apply to library search products. This difference may then explain why our EDS search query statistics increased so dramatically. A second potential reason for this increase is that more users may be refining their searches not through query revisions but through use of the facets or limiters, such as Source Type, Content Provider, or Subject, that EDS offers. An EBSCO Publishing (2013) tutorial explains that applying a limiter or limiters will execute new searches, recording new search statistics within EDS. So if a user searches for the query "home schooling”, reviews the search results, and then narrows the search results to the Source Type: Book, EDS will record two searches, one for the initial query and a second for when the Source Type limiter was applied. The library faculty teach and recommend the use of limiters during reference and instruction sessions, so the possibility that users are actually refining their searches through these or other methods is very encouraging. The goal is to connect users with the materials they need; the increase in search statistics indicates they may be using different strategies to accomplish this goal.

Our comparisons of Fall 2011 and Fall 2012 usage totals for Abstract, Full Texts Retrieved, Smart Links To, and Custom Links Out statistics also lent beneficial insights. Abstract usage increased 7.3\% year over year. This may be the result of advice dispensed by library faculty; in interactions with students, the librarians often recommend reading or skimming abstracts before downloading dozens of articles. The number of Full Texts Retrieved decreased 7.8\% from year to year. This statistic, taken in 
conjunction with the increase in Abstract usage, may be a positive development: If students refrain from downloading materials they do not need because they have read abstracts and decided certain materials are irrelevant, a decrease in full-text downloads is logical and not a negative consequence. Smart Links To statistics dropped 30.0\% from 2011 to 2012, but this is probably the result of algorithmic and/or technical changes on the vendor side, rather than a change in user behavior. For instance, if the quality of the records for a specific database improved, records from that database may have climbed in the search results. If those records previously Smart Linked full text to higher ranking records from other databases, the improved ranking of records from the specific database may have eliminated the need for Smart Links to other databases. The increase (55.5\%) in usage of Custom Links Out is logical given the growth in proprietary partnerships EBSCO has developed with other publishers, including JSTOR, LexisNexis, Thomson Reuters, Accessible Archives, and more (EBSCO Publishing, 2012). As an example of the growth in custom links available within EDS between Fall 2011 and Fall 2012, during Spring 2012, the Digital User Experience Librarian worked with EBSCO support staff to add custom links for 30 Alexander Street Press databases, including five streaming video collections, to EDS. The addition of custom links is critical for two primary reasons: First, the quicker users can find the materials they need to complete their assignments and research, the more time they can devote to assessing the materials they locate. Second, the more content providers whose publications are automatically indexed within EDS, the more robust the service is, and the more we can demonstrate to students and faculty alike that they are more likely than not to find something of value within EDS.

After reviewing our campaign processes, analyzing our usage statistics, and discussing our campaign outcomes, we came away with a few ideas as to what we would do differently next time around. In the course of designing the image for the promotional items, we learned that Media \& Marketing would have preferred to play a more active role in our task force, and they would have liked to be engaged earlier in the project. While members of Media \& Marketing were invited to join library task force meetings early on in the planning process, in the future we would more diligently follow-up to ensure the invitation was received. It would have been helpful for a Media \& Marketing employee to 
actually serve on the task force in order to streamline communication between the library and Media \& Marketing, particularly in regards to institutional requirements for designs and timeframes for different components of the project.

Additionally, in defining the target audience for the campaign, the task force decided to market EDS directly to students, rather than using faculty advocacy, because we could not guarantee faculty would buy into EDS and spread the message. However, we acknowledge the value of faculty resource recommendations; we know that many students use the resources their professors and instructors have explicitly recommended. Perhaps not all of the faculty would have promoted EDS to their classes, but additional enthusiasm from this esteemed population would have helped further spread our message to students. Just as we targeted undergraduate students in this campaign, in the future we would also target a segment of the faculty with measurable reaches into the student population and whom we think would be most likely to adopt - or have already adopted - EDS. For example, IU Kokomo requires all freshmen to take a freshmen learning course, which is a basic composition or public speaking course combined with an introductory social science, humanities, or science course. Since EDS lends itself well to the broad nature and variety of potential research topics in these classes, integration into the freshmen learning courses is a natural fit. In particular, to target our message to specific courses, we could explore integrating marketing announcements into the university's course management system. Regardless of the next resource or service that the library promotes, integrating the promotion with specific courses and forming closer partnerships with faculty are steps we are very likely to consider in order to boost our potential for success.

The remaining changes we would make for our next promotional campaign would be to add more user-engagement opportunities. For our EDS marketing campaign, we had only two primary events at which users could engage with our faculty librarians and ask questions: the open house and the brown bag session. In the future, we would incorporate the campaign into library instruction sessions with classes, as well as perhaps create competitive or game aspects in order to incentivize participation. Taking a cue from summer reading programs at many public libraries, such as the Ann Arbor District Library (2013), 
one idea is to award students with points or badges for attending promotional events and asking librarians questions about how the promoted resource or service can help them with a specific project; the points would then be redeemable for prizes at the conclusion of the campaign. To draw more users to events, we would consider offering additional incentives beyond gaming features, though, such as food or small prizes. Based on comments we received during our open house, we believe that students best understand the utility of EDS after they have had an opportunity to test it for themselves. The changes we would make to our promotional campaign would draw additional users to test the product, thereby allowing them to discover its power and benefits for their projects.

\section{Conclusion}

While we cannot deny that we would have been overjoyed had our promotional campaign caused an indisputable surge in all usage and user-engagement metrics, that wasn't the situation we experienced: Some statistics were better than expected, while others were not. Still, we cannot brush aside all of our efforts simply because we did not observe the usage increases we had initially sought. In fact, the decreases actually allowed us to take a closer look at our statistics and discuss how users may be interacting with EDS, rather than just reviewing the numbers. Since our inferences are currently based only on the usage statistics we collected, an area for exploration in the future would be to conduct usability studies with students and faculty to determine how they interact with EDS. We are particularly interested in learning whether our users are reading abstracts prior to downloading full-text articles and whether they see and use the Custom Links listed in the search results.

Beyond potentially gaining insight into how users use EDS, our library gained tremendous insights into how to conduct a cost-effective marketing campaign. One shortcoming of this campaign was that we did not determine at the outset how the results of the campaign would affect future promotional strategies for the library. A key task for our library, then, is to apply the lessons we learned from our EDS campaign in order to develop an overall library marketing plan. We anticipate building upon the electronic resources marketing tips from Wisniewski and Fichter (2007) to develop a marketing plan report, as recommended by Kennedy and LaGuardia (2013). The IU Kokomo Library has curated an 
extensive, high-quality, and deep collection for its user community in order to support the university’s teaching, learning, and research mission. Increasing awareness of the strength of this collection is a strategic priority for the library. Our EDS promotional campaign showed that a targeted and interdepartmental promotional campaign can increase the visibility of library resources and enhance relationships with user groups. Importantly, such an undertaking does not need to be expensive, particularly when existing talents and resources are used throughout the process. On the whole, then, our findings are encouraging and likely to lead to additional promotional campaigns so that we can continue to communicate the value of our library to our university community.

\section{References}

Ann Arbor District Library. (2013). Summer game | AADL summer game. Retrieved from http://play.aadl.org/

Berry, J. (1979, September 1). The “test of the marketplace.” Library Journal, 104(15), 1605.

Brannon, S. (2007). A successful promotional campaign: We can't keep quiet about our electronic resources. The Serials Librarian, 53(3), 41-55. doi:10.1300/J123v53n03_04

Conroy, B. (1984). Megatrend marketing: Creating the library's future. Journal of Library Administration, 4(4), 7-18. doi:10.1300/J111V04N04_03

Dillon, D. (2003). Strategic marketing of electronic resources. The Acquisitions Librarian, 14(28), 117134. doi:10.1300/J101v14n28_07

Dragon, A. C., \& Leisner, T. (1984). The ABCs of implementing library marketing. Journal of Library Administration, 4(4), 33-47. doi:10.1300/J111V04N04_05

Dugan, M. (2011). “Database of the week”: Successfully promoting business databases to faculty. Journal of Business \& Finance Librarianship, 16(2), 159-170. doi:10.1080/08963568.2011.556351

EBSCO Publishing. (2013). EBSCO Discovery Service statistics explained [PowerPoint slides]. Retrieved from http://support.epnet.com/knowledge_base/detail.php?topic=\&id=5970\&page=1

EBSCO Publishing. (2012). What is the difference between EBSCO CustomLinks and SmartLinks? Retrieved from http://support.ebscohost.com/knowledge_base/detail.php?id=1295

Empey, H., \& Black, N. E. (2005). Marketing the academic library: Building on the “@ your library” framework. College \& Undergraduate Libraries, 12(1-2), 19-33. doi:10.1300/J106v12n01_02

Fagan, J. C. (2009). Marketing the virtual library. Computers in Libraries, 29(7), 25-30. Retrieved from http://www.infotoday.com/cilmag/ 
Fleming, H. R. (1993). Library CPR: Savvy marketing can save your library. Library Journal, 118(15), 32-35.

Indiana University 2012-13 Fact Book. (n.d.). Retrieved from

http://www.iu.edu/ uirr/reports/standard/factbook/2012-13/University/Factbook.pdf

Indiana University Kokomo Campus 2012-13 Fact Book. (n.d.). Retrieved from http://www.iu.edu/ uirr/reports/standard/factbook/2012-13/Kokomo/Factbook.pdf

Kennedy, M. R., \& LaGuardia, C. (2013). Marketing your library's electronic resources: A how-to-do-it manual for librarians. Chicago: Neal-Schuman.

Making it clear in Salt Lake City. (1993). American Libraries, 24(10), 908. Retrieved from http://www.americanlibrariesmagazine.org/

Mathews, B. (2009). Marketing today’s academic library. Chicago: American Library Association.

Maxwell, K. (2009, April 23). Wordle. In Macmillan Dictionary online. Retrieved from http://www.macmillandictionary.com/us/buzzword/entries/wordle.html

Metz-Wiseman, M., \& Rodgers, S. L. (2007). Thinking outside of the library box: The library communication manager. The Serials Librarian, 53(3), 17-39. doi:10.1300/J123v53n03_03

Singh, R. (2004). Branding in library and information context: The role of marketing culture. Information Services \& Use, 24(2), 93-98.

Singer, G., Norbisrath, U., \& Lewandowski, D. (2013). Ordinary search engine users carrying out complex search tasks. Journal of Information Science, 39(3), 346-358. doi:10.1177/0165551512466974

Thornton-Verma, H. (2011, November 15). Discovering what works: Librarians compare discovery interface experiences. Library Journal, Supplement, 14.

Vaughan, J. (2012). Investigations into library web-scale discovery services. Information Technology and Libraries, 31(1), 32-82. doi:10.6017/ital.v31i1.1916

Wisniewski, J., \& Fichter, D. (2007). Electronic resources won't sell themselves: Marketing tips. Online, 31(1), 54-57. Retrieved from http://www.infotoday.com/online/

Wood, E. J. (1983). Strategic planning and the marketing process: Library applications. Journal of Academic Librarianship, 9(1), 15-20.

Woods, S. L. (2007). A three-step approach to marketing electronic resources at Brock University. Serials Librarian, 53(3), 107-124. doi:10.1300/J123v53n03_08 